\title{
Climate Change Vulnerability and Response Measures for Enhancing Coping Strategies by Marginalized Groups in Meru County, Kenya
}

\section{Lucy Karega Njeru, PhD}

\begin{abstract}
Department of Agricultural Economics and Extension, University of Embu P. O. 6-60100 Embu, Kenya.
\end{abstract}

\section{ARTICLE INFO}

Article No.: 110217162

Type: Research

DOI: 10.15580/GJAS.2017.10.110217162

Submitted: 02/11/2017

Accepted: 08/11/2017

Published: 12/12/2017

${ }^{\star}$ Corresponding Author

Lucy Karega Njeru

E-mail: lucykarega@gmail.com;

karega.lucy@embuni.ac.ke

Keywords:

Agriculture, Climate Change, Policy Measures, Coping Strategies, Marginalized
ABSTRACT

Kenya like other sub-Saharan African countries face uncertainty and potential risks of climate change and have been integrating climate considerations into various legal and governance instruments. Progress has been made in planning and implementing policies, projects and programs in key economic sectors in order to enhance coping strategies and participation of marginalized groups in policy making. The research assessed the climate change response measures in Meru County and focused on 20 stakeholders from each of the sampled Sub County namely Igembe North, Igembe Central and Igembe South. The research was guided by two objectives and a stakeholders' questionnaire was used to solicit the data that was required for the research. The collected data was cleaned, coded and analyzed using SPSS version, while frequency tables and percentages summarized and presented the quantitative results. The results showed varied risks faced in Igembe in the context of climate change, for instance food and water insecurity which was very dominant. The results revealed some policy being undertaken by the County Government and other stake holders to enhance participation of marginalized groups in policy matters with $(83.3 \%)$ policy on community capacity building through environmental education, encouraging adaptation of high value crops $(81.7 \%)$ and policy on social protection for instance, conflict resolution education (48.3\%). The finding further revealed key Climate Change Actors in the Count, for instance; the Ministry of Agriculture, Kenya Forest Station, Food and Agriculture Organization among others. These findings will contribute to the policy-makers, development practitioners and governments' efforts of finding more innovative ways of creating targeted interventions for promoting climate resilience, enhancing coping strategies and participation of marginalized groups in policy issues. 


\section{INTRODUCTION}

Climate change represents one of the world's greatest human development challenges. Global temperatures and sea levels are rising and will continue to do so throughout the 21 st century. Human activity, particularly deforestation and the burning of fossil fuels, is driving this change by increasing atmospheric concentrations of carbon dioxide and other greenhouse gases (GHGs) (Füssel \& Klein, 2006). As a result, the world is experiencing greater weather extremes, changes in rainfall patterns, heat and cold waves, and increasing droughts and floods. These phenomena have a negative impact on the environment and on people's lives and livelihoods. According to Goh (2012), marginalized groups in the poorest regions are particularly affected, even as they are least responsible for these changes. As such, short-term disasters and the longer-term effects of climate change can threaten people's abilities to lead long and healthy lives, to be knowledgeable, to have a decent standard of living, and to participate in community life with dignity and self-respect. Climate change not only threatens efforts to reach the Millennium Development Goals (MDGs), but could also lead to major reversals for certain groups in terms of income, health and education outcomes, while increasing global inequities. Climate change responses can also perpetuate inequality if not carefully designed (Field, 2012).

The effects of climate change and related disasters have the potential to adversely impact the majority of Kenyans given that about $75 \%$ of the population depends directly on land and natural resources for their livelihoods (Adimo, Njoroge, Claessens, \& Wamocho, 2012). In recent years, there has been increased attention to climate change due to its impacts on the lives of Kenyans. This has been mainly due to an increase in intensity and frequency of extreme climate events such as severe droughts and flooding. These extreme events have had negative socio-economic impacts on almost all sectors in the Kenyan society such as health, agriculture, livestock, environment, hydropower generation, and tourism thus impacting negatively on the objectives set out in the Government's Vision 2030 development plan.

The degree to which climate change affects human development depends on levels of both risk and vulnerability. Vulnerability is different from risk. Whereas risk is about exposure to external hazards over which people have limited control, vulnerability is a measure of people's capacity to manage such hazards to prepare for, cope with, and recover from them without long-term, potentially irreversible losses of well-being (UNDP, 2013). When for instance, tropical cyclones and floods strike a city like Mombasa, they expose the whole city to risks. However, people's vulnerabilities are concentrated among those living in the overcrowded, makeshift homes of the slums along the coastal region. In any country, the processes by which risk is converted into vulnerability are shaped by the underlying state of human development, including inequalities in income, opportunity and political power that marginalize the poor (Adimo et al., 2012). High levels of economic dependence on agriculture, lower average incomes, already fragile ecological conditions, and location in areas that face more extreme weather patterns are all vulnerability factors.

According to UNDP (2009) coping strategy is the response to actual or expected climatic conditions or their effects that have a negative impact on human development. It is a broad concept that can be used to describe a variety of ways to reduce vulnerability. Adaptation to the negative impacts of climate change generally takes place in two ways: anticipatory (before impacts take place) and reactive (as a response to initial impacts). Adaptation measures can be implemented by public and private actors. Action therefore must be taken now by all national and international stakeholders to find sustainable win-win solutions to adapt to the effects of climate change. Efforts must simultaneously be made to curb future risks through emission reductions, while ensuring sustainable, climate-resilient growth and greater energy access for the poor (Adimo et al., 2012). It is therefore against this background that this research sought to carry out an assessment of climate change vulnerability in Meru County.

\section{Statement of the Problem}

Kenya's economy depends mainly on agriculture with smallholder agriculture accounting for about $80 \%$ of total production and $70 \%$ of marketed agricultural produce. Continued improvement on the productivity of this sector is therefore necessary for increased production. However, despite Government efforts to make agriculture more productive and profitable to small holder farmers, these farmers are not able to fully exploit the agricultural potential as they are faced with various risks due to negative impacts of climate change. Reducing negative impacts of climate change on the environment and on people's lives and livelihoods is a major limitation because of the high level of vulnerability for most Kenyan.

There are several policy and/or response measures that can be taken by the County Governments and other stakeholders, including civil society, private Sector and development partners in enhancing coping strategies and participation of marginalized groups. The County also has key climate change actors who undertake several activities in their respective thematic areas. However, information on these policy intervention measures in the County are poorly documented and understood, which make it difficult for Kenyan leaders and their development partners to formulate innovative strategies for promoting climate resilient livelihoods through enhancing community coping strategies and participation of marginalized groups in policy making in the County. This study will provide the missing 
information, which can be used to make informed decision on how to improve climate resilient livelihoods for the marginalized groups.

\section{Purpose of the Research}

To promoting climate resilient livelihoods through enhancing community coping strategies and participation of marginalized groups in policy making in Meru County.

\section{Objectives of the Research}

The research was aimed at achieving the following objectives:-

i. To explore policy undertaken by the County Government in promoting climate resilient livelihoods and enhancing coping strategies and participation of marginalized groups in policy making in Meru County.

ii. To determine the key climate change actors in the County and identify the activities they undertake in their respective thematic areas.

\section{RESEARCH METHODOLOGY}

\section{Description of the Study Area}

The research was carried out in three Sub Counties in Meru County. These were:- Igembe North, Igembe Central and Igembe South. These are the main producer of Khat (Miraa), but it is ironically ranked among the areas with the highest level of poverty, unemployment, acute child malnutrition and illiteracy levels in the County. Cases of climate change, e.g. change in rainfall pattern, prolonged drought, landslides, large gully formation have been experienced in the region in the last 3 years.

\section{Research Design}

This research adopted descriptive survey design which is simple to execute and can yield important information about a phenomenon. According to Kothari (2008), the design concentrates more on conditions which have already existed, practices which are held, and processes which are on-going as well as new trends. The design can create a detailed description of a phenomenon thus, it was appropriate to assess climate change vulnerability in Igembe region.

\section{Target Population and Sampling Procedure}

This project targeted in Igembe region who included:County Government officials, private sector ,development practitioners and farmer representatives. Twenty of these stakeholders were sampled from each of the three Sub-Counties to give a total of sixty respondents who acted as a target population for this preliminary study for the project. Kendall (2007) confirmed that a target population is the one the researcher uses to generalize the study results. Relevant data for the research was solicited by use of a semi structured questionnaire which was duly completed by the stake-holders.

\section{Instrumentation and Data Collection Procedures}

A self-administered questionnaire with information on an assessment of climate change vulnerability in Meru County, developed by the researcher with open and closed-ended items, was used for the main stakeholders in the agricultural sector in Meru County. The questionnaires' content validity was ascertained by five extension experts while a pilot test involving 30 stake holders was conducted to determine its reliability, which was $0.83 \alpha$. This was above the 0.70 minimum acceptable for educational research at a significance level of 0.05 set a priori.

\section{Data Analysis}

Immediately after the data was collected questionnaires were examined for completeness, cleaned and then coded using SPSS software. Analysis was done by both quantitative and qualitative techniques and frequency tables, charts and percentages were used to summarise and presents the results.

\section{RESULTS}

A respondent's age was important in determining the average age of stakeholders who participated in the research in the County. Most of the stakeholders 53.3\% were $41-50$ years while $26.7 \%$ aged between 31 and 40 years. $11.7 \%$ were 50 years and above with only $8.3 \%$ who had between 20 and 33 years of age. In terms of formal education, $38.3 \%$ had tertiary education, $43.3 \%$ had secondary education and $8.3 \%$ had primary education with the remaining $1.7 \%$ lacking formal education. The gender of the respondent was composed of $70 \%$ male and $30 \%$ female.

\section{An Assessment of Vulnerability to Climate Change}

Information on this section presents the main objectives of the research.

\section{Objective One}

To explore policy undertaken by the County Government in promoting climate resilient livelihoods and enhancing coping strategies and participation of marginalized groups in policy making in Meru County. 
The respondents were asked to indicate the major policy measures undertaken by the County Government in promoting climate resilient livelihoods and enhancing coping strategies and participation of marginalized groups in policy making in Meru. Their responses are indicated in Table 1.

Table 1: Policy Measures Undertaken by County Government in Meru County

\begin{tabular}{lll}
\hline Measures by county governments & Frequency & Percentage \\
\hline Encouraging many stakeholders with differing interest & 27 & 45.0 \\
Encouraging small holder involvement on policy issues & 27 & 45.0 \\
Farmer education and visit & 16 & 26.7 \\
Encouraging adaptation of high value crops & 49 & 81.7 \\
Health related interventions & 15 & 25.0 \\
Community capacity building through environmental education & 50 & 83.3 \\
Policy on social protection e.g. life skills and conflict resolution education & 29 & 48.3
\end{tabular}

Table 1 shows that community capacity building through environmental education (83.3\%), (81.7\%) encouraging adaptation of high value crops, policy on social protection e.g. life skills and conflict resolution education $(48.3 \%)$ and encouraging many stakeholders with differing interest (45\%) are some of the policy intervention measures that the County government should adopt in promoting climate resilient livelihoods and enhancing coping strategies and participation of marginalized groups in policy making in Meru County. This is in line with the findings by Fussel and Klein (2006) who argued that capacity development is essential to climate change adaptation and mitigation efforts, as well as broader environmental sustainability activities at regional, national and sub-national levels. Atela, Quinn and Minang (2014) gave examples of requisite capacities, for instance to collect, assess and share climate change information, including meteorological and socioeconomic data on human development risks and vulnerabilities; to support new public-private partnerships, and cross-border and regional cooperation; and to lobby, negotiate, and coordinate financial and technical assistance for promoting community resilience to climate change.

The findings also agree with those of UNEP (2008) that energy security and climate security are intertwined and should be addressed at the same time. Renewable energy is a win-win proposition for all countries. UNEP (2008) revealed that renewable energy provides opportunities for poverty alleviation and for satisfying the energy needs in rural and remote areas. It helps generate employment and creates local economic opportunities as well as curbing climate change and contributes to the protection of human health caused by air pollution.

There is a link between climate change and conflict. Climate change can exacerbate existing inequalities that can increase conflict and threats to local, national and regional stability and security (UNDP, 2013). Increased competition over unequal access to land, water and other key natural resources, for example, can erupt in violence. This has been the case in countries such as Chad, Sudan and Kenya and in particular some parts of Meru County where desertification and drought have heightened competition for land between settled cultivators and pastoralists thus, solutions to address underlying causes and prevention of future risks is paramount (Silvestri, Bryan, Ringler, Herrero \& Okoba, 2012). Climate change also causes people to leave their homes in search of better livelihoods, water, health and food security. In the early stages of droughts and changing rainfall patterns, farmers may reap fewer crops and pastoralists may find less pasture for their cattle. Households that previously engaged in temporary migration as a coping strategy may reach a tipping point and choose to leave permanently.

\section{Objective Two}

To determine the key climate change actors in the County and identify the activities they undertake in their respective thematic areas.

The respondents were asked to determine the key climate change actors in the County and identify the 
activities they undertake in their respective thematic areas. Their responses are indicated in Table 2 .

Table 2: Key Climate Change Actors in Meru County

\begin{tabular}{|c|c|c|}
\hline No. & Actors & Activities \\
\hline 1. & $\begin{array}{l}\text { FAO (Food and Agriculture } \\
\text { Organization) }\end{array}$ & $\begin{array}{l}\text { - Currently offering good agricultural practices } \\
\text { - Promotion of conservation agriculture }\end{array}$ \\
\hline 2. & MoA (Ministry of Agriculture) & $\begin{array}{l}\text { - } \quad \text { Conservation agriculture } \\
\text { - } \quad \text { Promotion of droughts tolerance crops }\end{array}$ \\
\hline 3. & $\begin{array}{l}\text { CARITAS } \text { (Catholic } \\
\text { Organisation, named after a } \\
\text { Latin word meaning Love } \\
\text { and Compassion) }\end{array}$ & $\begin{array}{l}\text { - Promotion of droughts tolerance crops } \\
\text { - Water harvesting, storage and conservation }\end{array}$ \\
\hline 4. & KFS (Kenya Forestry Station) & $\begin{array}{ll}\text { - } & \text { Re-afforestation and afforestation } \\
\text { - } & \text { Agroforestry }\end{array}$ \\
\hline 5. & $\begin{array}{l}\text { WARMA (Water Resources } \\
\text { Management Authority) }\end{array}$ & - Conservation of Water catchments through tree planting \\
\hline 6. & $\begin{array}{l}\text { ADS (Anglican Development } \\
\text { Services) }\end{array}$ & - Good agricultural practices \\
\hline 7. & $\begin{array}{l}\text { NEMA (National Environment } \\
\text { Management Authority) }\end{array}$ & $\begin{array}{l}\text { Examine land use patterns to determine their impact on the quality } \\
\text { and quantity of natural resources. } \\
\text { Carry out surveys, which will assist in the proper management } \\
\text { and conservation of the environment }\end{array}$ \\
\hline 8. & Public health & - Health intervention and nutrition \\
\hline 9. & $\begin{array}{l}\text { GTZ (Germany Technical } \\
\text { Cooperation Agency) }\end{array}$ & $\begin{array}{l}\text { - Promotion of energy saving Jikos, solar lamps and biogas } \\
\text { technology for households }\end{array}$ \\
\hline 10 & $\begin{array}{l}\text { SILC (Savings and Internal } \\
\text { lending Communities) }\end{array}$ & $\begin{array}{l}\text { - Water storage and sanitation } \\
\text { - } \quad \text { Conservation agriculture } \\
\text { - Promotion of drought tolerance crops }\end{array}$ \\
\hline
\end{tabular}

The table 2 reviews the key climate change actors in the County and identifies the activities they undertake in their respective thematic areas. As it is indicated in the table, many activities are undertaken to promote coping mechanisms, for instance GTZ involved in the promotion of energy saving jikos, solar lamps and biogas technology for the households. This conquers with the study by Atela et al., (2014) that increased energy and fuel efficiency through stronger regulations and their enforcement in industry, transportation, agriculture, buildings and appliances is of paramount importance. Incentives for the development and use of alternative renewable energies; development and use of cleaner technologies through participation in the Clean Development Mechanism and related mitigation programs should be enhanced and advocacy and support for new and expanded "green jobs" is pertinent (UNEP, 2008).

\section{CONCLUSIONS}

Based on the findings of the project research, the following conclusions were drawn

i. Climate change affected health primarily through increased vulnerability to poor health due to reduced food and water security; water-borne diseases associated with reduced water quality due to drought, favorable conditions for the spread of vectorborne and air-borne diseases and the direct link between temperatures and heat stress 
ii. Policy being undertaken by the County Government and other stake holders to enhance participation of marginalized groups in the County's policy issues were evident with majority of the respondents (83.3\%) citing community capacity building through environmental education and $(81.5 \%)$ indicating that encouraging adaptation of high value crops was paramount. Others were policy on social protection for example life skills and conflict resolution education and encouraging small holder involvement on policy issues among others.

iii. Policy being undertaken by the County Government and other stake holders to enhance participation of marginalized groups in the County's policy issues were evident with majority of the respondents (83.3\%) citing community capacity building through environmental education and $(81.5 \%)$ indicating that encouraging adaptation of high value crops was paramount. Others were policy on social protection for example life skills and conflict resolution education and encouraging small holder involvement on policy issues among others.

\section{RECOMMENDATIONS TO BE ADAPTED TO BUILD CLIMATE CHANGE RESILIENCE}

Based on the study conclusions, the following recommendations were made:-

i. The County leaders should strengthen existing efforts to empower the vulnerable and marginalized groups like the small holder farmers, and provide targeted assistance through public and private services. New jobs for the poor can be created and should be sustained for economic growth.

i. Participatory, policy planning is of paramount importance to include safer infrastructure, integrated water resource management, more sustainable access to public services and disaster risk management and preparedness thus the environment for school children can be better and to provide inputs needed for higher quality education

ii. County leaders should ensure that climate change debates and policy processes offers opportunities to engage women at all levels of decision-making, adopt gender-sensitive budgeting, provide better targeted public services based on gender needs, and address the underlying vulnerabilities and causes of factors that hinder gender equality and empowerment.

iii. The stakeholders should ensure that campaigns to reduce child mortality, improve maternal health, and combat HIV/AIDS, malaria and other diseases are strengthened through heightened awareness, increased capacities, better public services, information sharing, new and proven technologies, and better targeted financing.

iv. Local leaders should ensure social protection and psychosocial support that includes life skills and conflict resolution sensitization and other programs to support livelihoods and community functioning.

v. The stakeholders should strengthen community capacity-building including environmental education for child-friendly schools and spaces, microenterprises for women, education for sustainable development, and vocational training.

vi. The County Government should ensure employment of adequate number of agriculture extension officers and ensure better targeted financing geared towards farmer visit and trainings.

\section{RECOMMENDATION FOR FURTHER RESEARCH}

In order to determine whether the situation is different in other areas, other researchers should replicate the study in order to come up with a more comprehensive program for promoting climate resilient livelihoods and enhancing participation of marginalized groups in policy making in Kenya.

\section{REFERENCES}

Adimo, A. Njoroge, J. Claessens, L., \& Wamocho, L. (2012). Land use and climate change adaptation strategies in Kenya. Mitigation and Adaptation Strategies for Global Change, 17(2), 153171.

Atela, J. Quinn, C. \& Minang, P. (2014). Are REDD Projects Pro-poor in their Spatial Targeting? Evidence from Kenya. Applied Geography, 52, 1424.

Field, C. (2012). Managing the Risks of Extreme Events and Disasters to Advance Climate Change Adaptation: Special Report of the Intergovernmental Panel on Climate Change. Cambridge University Press.

Füssel, H. \& Klein, R. (2006). Climate Change Vulnerability Assessments: An Evolution of Conceptual Thinking. Climatic Change, 75(3), 301329.

Goh, A. (2012). A literature Review of the GenderDifferentiated Impacts of Climate Change on 
Women's and Men's Assets and Well-being in Developing Countries. International Food Policy Research Institute, CAPRi Work.

Silvestri, S., Bryan, E., Ringler, C., Herrero, M., \& Okoba, B. (2012). Climate Change Perception and Adaptation of Agro-pastoral Communities in Kenya. Regional Environmental Change, 12(4), 791-802.

UNEP (2008). Green Jobs: Towards Decent Work in a Sustainable, Low-Carbon World. Report
Commissioned and Funded by UNEP, as part of the Joint UNEP, ILO, IOE, ITUC Green Jobs Initiative.

UNDP (2009). Linking Climate Change Policies to Human Development Analysis and Advocacy. A Guidance Note for Human Development Report Teams, November 2009.

UNDP (2013). Human development report 2013. New York.

Cite this Article: Njeru LK (2017). Climate Change Vulnerability and Response Measures for Enhancing Coping Strategies by Marginalized Groups in Meru County, Kenya. Greener Journal of Agricultural Sciences, 7(10): 275-281, http://doi.org/10.15580/GJAS.2017.10.110217162. 